\title{
Understanding Racially Diverse Community Member Views of Obesity Stigma and Bariatric Surgery
}

\author{
Grace F. Chao ${ }^{1,2,3}$ (1) Adrian Diaz ${ }^{1,2,4} \cdot$ Amir A. Ghaferi ${ }^{5,6} \cdot$ Justin B. Dimick ${ }^{5,6} \cdot$ Mary E. Byrnes $^{5,6}$
}

Received: 8 June 2021 / Revised: 16 January 2022 / Accepted: 23 January 2022 / Published online: 27 January 2022

(c) The Author(s), under exclusive licence to Springer Science+Business Media, LLC, part of Springer Nature 2022

\begin{abstract}
Purpose The obesity epidemic poses serious challenges to health equity. Despite bariatric surgery being one of the most effective obesity treatments, utilization remains low. In this context, we explored public perceptions of bariatric surgery, centering voices of Black individuals.

Materials and Methods Semi-structured interviews with individuals who have never considered bariatric surgery with purposive sampling to ensure the majority of participants were Black. Transcripts were iteratively analyzed. We employed an Interpretive Description framework to arrive at a collective description of perceptions of bariatric surgery.

Results Thirty-two participants self-identified as 88\% female, 72\% Black, 3\% Hispanic, 3\% Pacific Islander, 3\% Mixed Race, and 19\% White. Participants reported a complex interplay of deeply held, stigmatized beliefs about identity. According to the stigma, persons with obesity lacked willpower and thus were considered devalued. Participants internalized this stigma, describing themselves with words like "glutton," "lazy," and "slack off." Because stigma caused participants to view obesity as resulting from personal failings alone, socially acceptable ways to lose weight were discipline through diet and exercise. Working for weight loss was "self-love, self-discipline, and determination." Thus, bariatric surgery was illegitimate, a "shortcut to weight loss" or "easy way out," since it was outside acceptable methods of effort.

Conclusion This qualitative study of community members who qualify for bariatric surgery shows obesity stigma was the main reason individuals rejected bariatric surgery. Obesity was stigmatizing, but undergoing bariatric surgery would further stigmatize individuals. Thus, healthcare providers may be instrumental in increasing bariatric surgery uptake by shifting social discourse from stigmatized notions of obesity towards one focusing on health.
\end{abstract}

Keywords Community health $\cdot$ Bariatric surgery $\cdot$ Obesity stigma

Key Points

- Obesity stigma was the most important barrier to consider bariatric surgery.

- This stigma caused individuals to think they needed personal responsibility alone.

- As such, bariatric surgery was considered cheating and further stigmatizing.

Grace F. Chao

grace.f.chao@yale.edu

1 National Clinician Scholars Program at the Institute for Healthcare Policy and Innovation, University of Michigan, 2800 Plymouth Road, Building 14, Suite G100, Ann Arbor, MI 48109, USA

2 Veterans Affairs Ann Arbor, Ann Arbor, MI, USA

3 Department of Surgery, Yale School of Medicine, New Haven, CT, USA

\section{Introduction}

The obesity epidemic poses serious challenges to health equity in the USA. A disproportionate number of Black individuals suffer from obesity. In adults, $50 \%$ of non-Hispanic Blacks were reported to have obesity $\left(\mathrm{BMI} \geq 30 \mathrm{~kg} / \mathrm{m}^{2}\right)$ compared to $42 \%$ of non-Hispanic Whites [1]. Bariatric surgery is a safe, effective, and durable treatment for obesity and related comorbid conditions [2,3]. Despite this, less than $1 \%$ of individuals who would benefit utilize bariatric surgery

4 Department of Surgery, The Ohio State University College of Medicine, Columbus, OH, USA

5 Center for Healthcare Outcomes and Policy, University of Michigan, Ann Arbor, MI, USA

6 Department of Surgery, University of Michigan, Ann Arbor, MI, USA 
[4]. Moreover, the current demographics of patients undergoing bariatric surgery do not mirror the population reported to have obesity. According to 2020 US Census data, 14.2\% of Americans identify as Black and $57.8 \%$ as non-Hispanic White [5]. However, only $18 \%$ of bariatric surgery patients identify as Black [6].

Few studies attempt to understand why there are low utilization rates, particularly among Black individuals [7-9]. These studies were also conducted prior to the widespread use and familiarity of the general public with laparoscopic sleeve gastrectomy. Other studies have focused on individuals who have already expressed interest in bariatric surgery, examining individual, provider, and systems barriers to completing surgery [10-14]. Because the patients in these studies have already initiated the surgery process, studies thus far have centered experiences of White individuals. Additionally, few studies have examined how community members of the general public, rather than already-established patients, understand bariatric surgery [15].

Thus, in this study, we centered Black voices to understand why uptake of bariatric surgery is so low. We conducted semi-structured interviews of the general public, oversampling Black individuals, to better understand how community members conceptualize bariatric surgery. We then performed a qualitative analysis to formulate a conceptual model for how community members understand what bariatric surgery is and whether it is appropriate for them personally.

\section{Methods}

\section{Study Design}

This report is part of an exploratory qualitative study to investigate barriers to bariatric surgery in a sample of mostly Black individuals in the community. The study was approved by the University of Michigan Institutional Review Board (HUM\#00,170,297).

\section{Interview Participants}

Purposive sampling was used to recruit our cohort, using two strategies to achieve information power [16]. First, we partnered with a health center predominantly serving Black individuals, Western Wayne Family Health Centers (WWFHC) in Inkster, a community that is 73.7\% Black [17]. All recruitment materials were developed in conjunction with our community partner. Our community partner also shared recruitment materials with organizations working to increase representation of Black individuals in research. Researchers also placed recruitment posters at libraries and stores. Second, we supplemented sampling with outreach via the Michigan Medicine research portal. During recruitment, demographics of the cohort were reviewed to ensure sampling led to a cohort with mostly Black participants. Our goal was to center the voices of Black community members given that most studies focus on narratives of White individuals. By including Black experiences, we hoped to glean new information about perceptions of bariatric surgery. The goal of our study was not to draw racial comparisons but rather to include new narratives that would aid us in our clinical practice to improve the health of all patients.

Participants were asked to select a pseudonym for purposes of humanizing the data which is reported as such. Community members were from Southeastern Michigan. Participants were included if aged 18 or older, met NIH criteria for bariatric surgery (BMI $\geq 40 \mathrm{~kg} / \mathrm{m}^{2}$ or BMI $\geq 35 \mathrm{~kg} /$ $\mathrm{m}^{2}$ with an obesity-related comorbid condition), and had never considered bariatric surgery. Participants were compensated for their time upon completion of their interview. Participants were asked to self-identify race/ethnicity (e.g., "Black," "African American"), age, and insurance status.

\section{Interview Procedures}

Interviews were conducted by two team members (GFC and MEB) in February to August 2020. Prior to COVID19 distancing measures, authors met participants face-toface at WWFHC or University of Michigan. After March 13 , interviews were conducted over secure videoconference or telephone. All participants gave consent to the information provided in the study prior to a 35-90-min interview. Interviews were audio-recorded and transcribed verbatim by an external HIPAA-approved transcriptionist with identifying information redacted. Transcripts were reviewed for accuracy.

The objective of interviews was to understand participants' experiences with their health and perceptions of bariatric surgery. In conjunction with WWFHC, we created a semi-structured interview guide (Supplementary Material 1). We used an active interview style [18] to allow participants to expand on ideas important to them.

\section{Data Analysis}

An exploratory, iterative method was used to code transcripts. Researchers (GFC and MEB) independently opencoded four interviews examining for patterns, concepts, and constructs. The team met to discuss where codes converged and diverged to create a coding scheme. The codebook was tested on five transcripts and revised to capture the participant experience. Coded portions were examined as a team to refine codebook definitions. The first author then coded all interviews using eclectic coding, [19] a method that leaves room for data that did not fit the codebook and for in vivo coding. All transcribed interviews were coded using 
MaxQDA20 (VERBI Software, Berlin, Germany, 2019), a computer-assisted qualitative data analysis software.

When coding was completed, the team met to discuss patterns and "issues around which codes cluster" [20] emerging from coded data to build a conceptual model using an Interpretive Description framework [21]. Though we did not ask about meanings bariatric surgery had on personal identity, participants spoke openly about how they felt people who chose bariatric surgery were of a certain character they did not want to be. We found that participants shared these perceptions of bariatric surgery regardless of race. Thus, our results are from the voices of participants rather than guided by investigator bias and manifest the promise of qualitative methodology providing emergent data [22].

As part of the iterative process of qualitative research, we returned to existing scholarship about stigma based on physical appearance [23]. We examined how our data converse with existing scholarship and developed a coherent, collective story of community members with obesity who have not pursued bariatric surgery.

\section{Results}

The thirty-two participants (demographics in Table 1) in our study described their struggle with having obesity as a stigma and reported obesity conveyed a message to others in society about their character. Because the totality of our sample discussed the "stigmatism that comes with... being an overweight person" (Janettie, 57, Female, White), we turned to the foundational work of medical sociologist Erving Goffman to contextualize our findings [23].

In our analysis, we used Goffman's theory of stigma as a prism in which to view our results. In other words, how does obesity as a visible stigma affect the ways participants formulated ideas about identity and weight loss? In Goffman's framework, advanced in public health, [24] stigma is a social or physical characteristic that causes society to deny acceptance of an individual. Goffman described how individuals (both stigmatized persons and "normals") operationalized stigma in everyday life is the mechanism through which society marginalizes groups. In so doing, he theorized that individuals are devalued because of difference which could be visible (skin color, physical impairment) or invisible (deafness, unemployment).

As our conceptual model in Fig. 1 demonstrates, participants in our study report a complex interplay of feelings about bariatric surgery that negotiate deeply held, stigmatized beliefs about identity and their bodies. The model shows how participants developed a shared framework for how stigma affects how they see their bodies and bariatric surgery. Further exemplar quotes are included in tables.
Table 1 Participant characteristics

\begin{tabular}{ll}
\hline Characteristics & Participants, $N=32$ \\
\hline Race/Ethnicity, no. (\%) & \\
Black or African American & $23(72 \%)$ \\
Hispanic & $1(3 \%)$ \\
Pacific Islander & $1(3 \%)$ \\
Mixed Race (Ghanaian White) & $1(3 \%)$ \\
White & $6(19 \%)$ \\
Sex, no. $(\%)$ & \\
Female & $28(88 \%)$ \\
Male & $4(12 \%)$ \\
Age, years, mean (SD) & $47.8(12.8)$ \\
Age range, no. (\%) & \\
$<45$ & $15(47 \%)$ \\
$45-65$ & $13(41 \%)$ \\
$>65$ & $4(13 \%)$ \\
Occupation, no. (\%) & \\
Not working & $3(9 \%)$ \\
Retired & $2(6 \%)$ \\
Student & $1(3 \%)$ \\
Working full-time & $21(66 \%)$ \\
Working part-time & $5(16 \%)$ \\
Privance type, no. (\%) & \\
Medicaid or Medicare & $18(56 \%)$ \\
No insurance & $10(31 \%)$ \\
Did not specify & $0(0 \%)$ \\
\hline & $4(13 \%)$ \\
\hline &
\end{tabular}

Note: Participants self-identified all presented demographic information in the table

\section{“It's My Own Darn Fault": Obesity as Stigma}

Individuals in our study explained the intricate ways they understood body size as a stigmatizing force in their social interactions. Many participants spoke about their struggles with obesity and weight loss through the eyes of others (Table 2). Participants reported an assumption with obesity is lack of self-control. Richara (31, Female, Black) shared:

[P]eople think you're not putting forth the effort. They don't know if there's an underlying condition...I never had a desire to be small or skinny, but...people don't see that. They don't understand that [and] just judge.

Richara's narrative illustrates the general society-held belief that persons with obesity were unable to control their bodies through eating and exercise. She and other participants also discussed how because obesity was a visible feature, it was, as Terrell (49, Male, African American) noted, "one of the last things in America you can be judged by." Because of this supposed lack of control, obese bodies were 


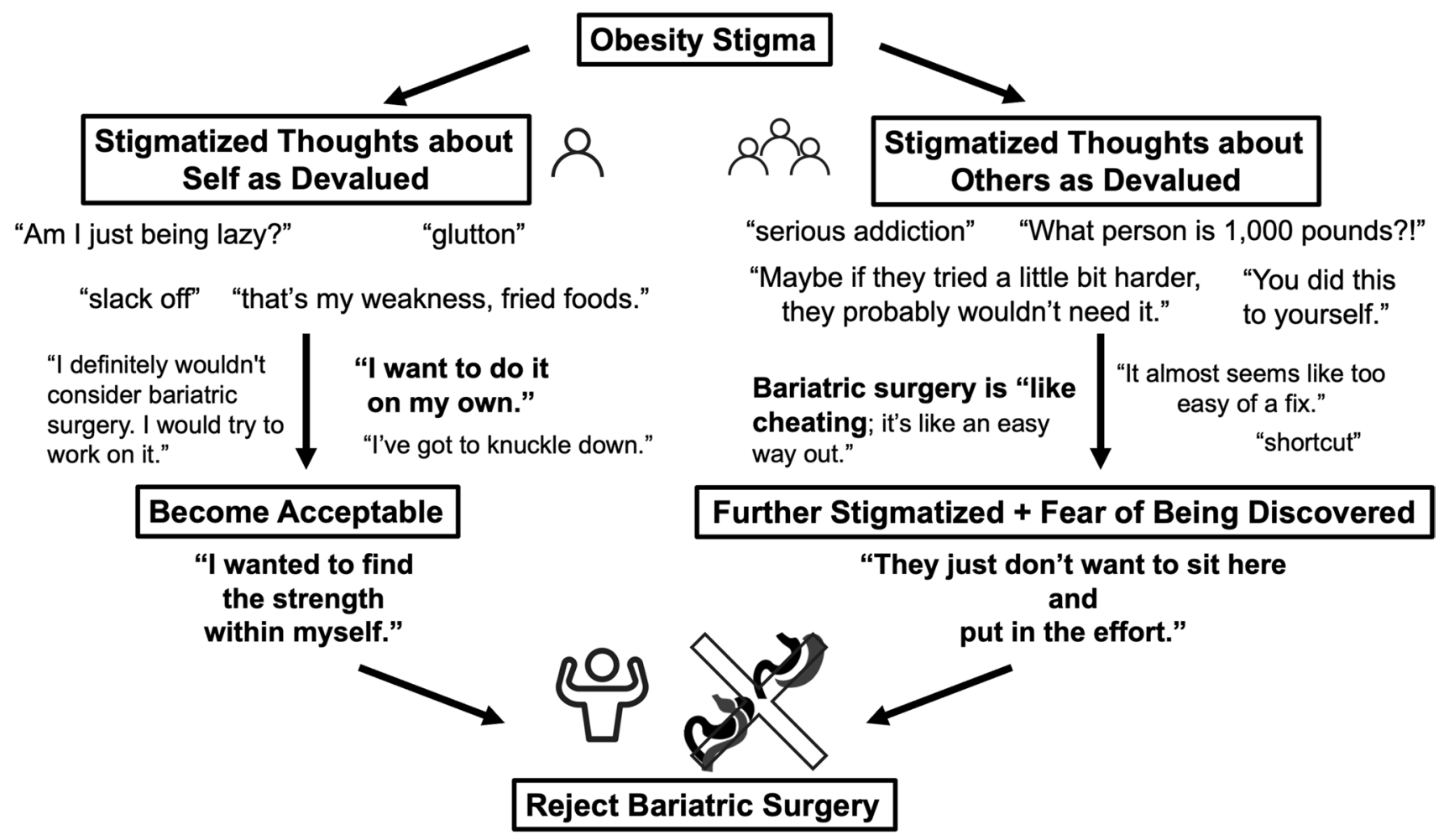

Fig. 1 Conceptual framework for obesity stigma as a prism to understand community member perceptions of weight loss and bariatric surgery. The figure depicts the conceptual framework for how obesity

considered a physical manifestation of innate weakness of character.

Participants internalized the stigmatized idea that obesity devalued them. As a result, participants often identified personal weakness as why they developed obesity. Paulina (44, Female, African American), when asked about weight loss in the media, stated:

[W]hen I watched the show, [the surgeon] puts them on a 1,200-calorie diet...I'm thinking to myself, high protein...either low carbs or no carbs. So basically, that's a piece of meat and vegetables. So I'm sitting up here like, can the meat be any way I want it to be?

[T]hat's my weakness, fried foods.

Even though explicitly asked about the media, she linked what was on television with what she considered her own personal character failings. Other participants listed items they felt to be associated with good character-eat vegetables, drink more water, exercise more-but followed these thoughts with self-disparaging comments that they did not engage in them vigorously. Some explicitly called themselves "lazy" or a "glutton" or noted they sometimes "slack off." Others expressed frustration at their loss for why they did not engage in these expected behaviors: stigma applied to participants themselves and others who chose bariatric surgery caused participants to reject bariatric surgery as a potential treatment for themselves

[O]ne person...was like..., 'why don't you just like exercise more on your bike?' And I'm like, 'well, DUH'... 'thank you for that revelation.'...I would do that if I like could figure it out. I was like, 'why don't, like you have this tic that you do, or you have this personality flaw. Like why don't you stop that? Because it's hard, right?' (Kyle, 37, Male, White)

As Kyle explained, it was not laziness preventing engagement in expected behaviors. Through sharing his story, he explains he equated his behaviors with other conditions such as a "tic" or a "personality flaw" which he could not simply stop.

\section{"I Want to Do It on My Own"}

Because participants viewed obesity as the result of individual responsibility, they also viewed weight loss as something they could and should control. In other words, participants spoke to how the socially acceptable way to lose weight was to discipline the body, to do weight-loss work. This discipline was described as willpower to follow rules of diet and exercise. As Jen (41, Female, Black) noted:

I have a challenge of just trying to lose weight and keep it off, but I just didn't think I was at that point 
Table 2 Stigmatized thoughts about self

Theme Exemplars

Stigma devalues individuals with obesity which participants internalized.

Because obesity is due to failure of personal responsibility, the socially acceptable way to become healthy is to personally discipline the body.
I know right now, and just from my experience, how people perceive you. The perception is, okay, this guy doesn't want to work out. $\mathrm{He}$ doesn't, he's not going to do things like walk, or, you know, he's big and whatnot and how, your attractiveness tends to go down towards. (Terrell, 49, Male, African American)

And for people that I'm closer with, like if I have a conversation of like, well, yeah, like I know these things. Like that's why I also like hate going to a dietitian because I'm like I actually know all of this stuff...I just don't do it, for various reasons. (Kyle, 37, Male, White) See, I've always been health conscious. I've had memberships all through the years at different health clubs, so I've always tried to stay in shape. Only in the last ten years did I get kind of off, you know...I don't know what I want to blame that on...And you know you've got to do the work. It's not going to happen by itself. (Christy, 68 Female, African American)

Yeah, the focus on you. Rather than saying, okay, let's help him with this problem, they were sort of like, let's just see how far across the finish line he's willing to go. (Terrell, 49, Male, African American)

No, not really. I just, you know, know what I think and what I feel like I should do. Like I say, at this weight that I am now, I just try to work on it. I don't want to get to be, you know, three, over, I just don't want to get any bigger than I am now, so I definitely wouldn't consider bariatric surgery. I would try to work on it now, yeah. (Donna, 64, Female, Black)

I don't know if I ever would [get bariatric surgery]... I think the discipline that I watched her have to have would be where I would want to go with just like the pre-surgery weight loss. (Donnie, 47, Female, African American) Because there's people around me who were talking about it [bariatric surgery], coworkers. Again, my cousin, my friend were talking about it. I was like, oh, okay. And I did some research...I just felt I hadn't tried a lot of things and put forth a lot of effort and things. So until I truly felt that I put in the work and nothing came of it, then I would say, okay, now this is the last resort. Let me look into this as far as getting rid of my diabetes or something like that. But I just don't feel like I've done enough. (Latoria, 33, Female, African American)

Because I honestly felt like my friend, one of my friends who lives in [location] who had [bariatric surgery], I was, she was, at one time, she was doing aerobics, she was hiking, very active. And I said, why are you doing that? You know how to change your diet and exercise. You don't need to do that. But I understand why she did it though. (Kim, 55, Female, African American) 
where I would need like surgery...[I]t kind of made me feel a little bad. It made me feel a little discouraged...[L]ike if I want to go on my own accord and do it and just be disciplined at doing it, I know that I can still do that.

Jen's doctor discussed bariatric surgery with her, but she wanted to lose weight on her "own accord" and "be disciplined." Another participant also shared his conviction in his control over his weight: "I don't think that I'm big enough to sit here and that I can't handle taking weight down myself" (Myron, 38, Male, Black).

In addition to putting in work to redeem a presumed lack of responsibility, stigma guided participants to connect this work to building good character. Diet and exercise were not only seen as adhering to social norms. Stigma also caused participants to see this work as building up virtuous versions of themselves. Christy (68, Female, African American) described this work:

But I think if you're...overweight, I really think you need to look at your, it's about self-love, self-discipline, and determination...You can change it around, because...it does matter...And it's just like connecting your mouth to your mind and to the self-love, the selfrespect...I chose to do it my way...

Taking responsibility to engage in weight loss was connected to virtues like "determination" and "reach[ing] my potential" (Latoria, 33, Female, Black). This diminished the fact that there were numerous legitimate physiologic, social, and structural reasons for why people suffer from obesity.

\section{People Who Are "Beyond Help" Get Bariatric Surgery}

Despite acknowledging how difficult it was to lose weight, all participants noted they were not "as bad" as "those people" who underwent bariatric surgery. Participants so strongly internalized obesity stigma that they even imposed the same stigma on others (Table 3). For participants, people who underwent bariatric surgery were a separate group of people to which participants themselves did not and did not want to belong. As Paulina (44, Female, African American) described bariatric surgery patients on television: "[T] hese were huge people. I'm talking about 700, 800, 1,000. What person is 1,000 pounds?!" Participants looked down

Table 3 Stigmatized thoughts about others, those who undergo bariatric surgery

Theme Exemplars

Participants saw themselves as separate from people who needed bariat- But then you get the ones [on the television show] that give up, and ric surgery, people who were "beyond help." they just be like, I can't do it, you know. I'm just going to eat myself to death. I don't want to be that person. (Paulina, 44, Female, African American)

You know, I don't know that maybe after liposuction if I wanted bariatric surgery to be a small one now, or to reduce the size of my stomach. I'm not really an over eater. I don't feel like tremendously overeating. (Vicky, 49, Female, Ghanaian White)

So like I try not to pass judgment, because like one of me and my sister's favorite show is like My 600-lb Life, and I'm like, no. And how do you say like you just feel so amazing when you eat food and how you don't stop it? How are they enabling them? But then it's like still judgment, because I don't, you know, I don't understand it. (Takayla, 31 Female Black)

One friend I was worried about...because she has been heavy all her life. [S]he always looks for quick fixes, in my opinion, in everything in her life. (Kim, 55 Female African American)

I think [my friend] had to lose like a certain amount of weight [for bariatric surgery]...[But] really, if we just did diet and lifestyle changes, we would be fine. You know, we weren't like beyond help or anything like that. (Elizabeth, 35 Female White)

It almost seems like too easy of a fix...I wanted to find the strength within myself... and have that as a backup...[S]ometimes it's kind of nice to pop in [to My 600-Pound Life] and...say, oh, God, I don't want to get there by any means, you know. It's almost more of a deterrent. Just like when you watch those hoarding shows, it's like, I've got to clean out my house. (Debbie, 63, Female, White)

My coworker, when he was talking about his aunt, oh, yeah, he was definitely negative because he was basically saying like, you know, she's not, she got the surgery, but she's not really trying. (Michelle, 34, Female, Black) 
on people who needed bariatric surgery. "Those people" who got bariatric surgery were even more devalued than they were.

Participants looked down on bariatric surgery patients because they were "beyond help" in two ways. First, participants attributed the, to them, extreme weight gain to an extreme lack of desire to change. When asked whether bariatric surgery could help someone's health, Michelle (34, Female, Black) responded: "I think...people, they really do have a serious addiction...And others, they try to take, not an easy way out... maybe if they tried a little bit harder, they probably wouldn't need it." Michelle believed, even with what she considered a serious health condition, individuals lacked personal responsibility. Second, those individuals' weight gain was so extreme they were no longer able to become "normal" without something drastic like bariatric surgery. Though all participants met NIH criteria for bariatric surgery, very few considered themselves candidates for bariatric surgery. LaKeisha (40, Female, Black) stated "I just don't know if I would ever qualify for it." Another participant shared:

My doctor has recommended [bariatric surgery] several times. And I was kind of offended...it was kind of...hurtful for me because I was thinking to myself, I can do it...I want to do it on my own. (Kim, 55, Female, African American)

To Kim, the most important part of weight loss was that it was done by the individual, and to be beyond self-help was shameful.

\section{Bariatric Surgery Is "Cheating"}

Participants deeply desired to distance themselves from bariatric surgery not only because people who choose to undergo bariatric surgery are extreme in negative ways, but also because bariatric surgery is considered cheating (Table 4). "[S]ome people may view it as a shortcut to weight loss, shortcut procedure." (Donna, 64, Female, African American) Only individuals who were beyond help were forced to cheat, to act outside socially acceptable methods of willpower and effort. As Christy (68, Female, African American) noted, bariatric surgery was undesirable because:

[Y]ou've got TV personalities that have had it done [and were] pressured to confessing that they had it... [L]ot of people didn't want to share that because they felt like it made them look weak. They couldn't do it on their own...[Y] ou saying I got control over this, I did this myself, I made up my mind to do it...[S] ome people want to not share that because for them... It takes some pride away from them...
Even if weight loss was achieved, individuals would have to maintain secrecy regarding their surgery because it was an admission of weakness, that they were cheaters.

Associated with bariatric surgery were also new fears of being exposed as a cheater. Individuals who lost weight through bariatric surgery might no longer have a visible stigma. However, they might have an additional invisible stigma-devalued for weakness causing obesity and then cheating. When asked who participants would talk to if they got bariatric surgery, many said they would hide it from family, friends, and colleagues. As Kim (55, Female, African American) put it: "With bariatric surgery...I know what other people think about it...that's just the easy way out." This fear of being discovered was also seen in participants' own desires to expose cheaters:

A friend of my sister's, to this day she has not admitted to having it. But my sister knows she had it because she lost weight too fast...[M]y sister said, 'I know she had it, but she's saying that, no, she did it naturally.'

(Sandra, 64, Female, African American)

Sandra revealed disdain for cheaters and how she and others exposed bariatric patients in private conversations. Many participants also shared news of a councilwoman who died from bariatric surgery. Those who shared this story attributed her death to going to a lesser-known hospital to hide she was getting bariatric surgery. Thus, this desire to hide cheating was widely acknowledged by participants, making bariatric surgery even more illegitimate.

\section{Discussion}

This is the first study to our knowledge examining perceptions of bariatric surgery in a diverse cohort that centers the voices of Black individuals. We set out to understand community members' perceptions of bariatric surgery to identify barriers to accessing surgery. We found participants spoke at length to ideas around stigma and socially acceptable and unacceptable avenues to lose weight. Because participants viewed their weight as personal responsibility, weight loss was also in their hands. Surgical intervention therefore was "cheating" because they "should" be able to discipline their bodies. As such, bariatric surgery was seen as an illegitimate and even further devaluing way to achieve weight loss.

The stigma framework first defined by Goffman has been applied to a myriad of medical illnesses such as cancer, [25] HIV-infected children [26], and mental illness [27]. Obesity, in Goffman's framework, because it is visible, leads to individuals being easily identified as a devalued individual. Because these participants all shared the stigma of obesity, they had a similar "moral career," learning what it means 
Table 4 Participant perceptions of bariatric surgery as cheating

\begin{tabular}{ll}
\hline Theme & Exemplar quotes
\end{tabular}

Bariatric surgery is cheating.

Bariatric surgery would lead to fear of being discovered as a cheater. American) American)
So there's some sort of stigma that if you have surgery you cheated or something. (Charo, 66 years old, Female, Hispanic)

I think I was just more surprised that she had decided to go that route [referring to best friend getting bariatric surgery]. I've watched her kind of diet and lose weight...It felt like, you know, it almost felt kind of like she was giving up. (Donnie, 47, Female, African

After the fact, like I said, like I'm not having success with doing it myself, quick fix in a sense too, you know, gaining control. (Takayla, 31, Female, Black)

[C]ertainly like thinner people will have this idea like it's like cheating, it's like an easy way out. Like you should just exercise or eat right. Like I do it, you should too. So it's kind of this like similar thing with how we see pick yourself up by the bootstraps, economically, kind of thing. (Kyle, 37, Male, White)

I think for myself, for me, I've got kind of let it go. I'm over it at that point. But I know just like, oh, she was lazy. You know, or she could have tried harder. She took the easy way out, you know. So I think things like that I also think that, you know, hold us up from getting it done. (Richara, 31, Female, African

[M]y stepdaughter went to Dominican Republic and had her entire body reconfigured. And she didn't really tell anybody... she says, 'And I've never had surgery. It's sort of like a badge of honor that this is, you did this all on your own, and you haven't had any help...So there's some sort of stigma that if you have surgery you cheated or something. (Charo, 66 years old, Female, Hispanic)

I think it was just like, I think in the beginning, people were just afraid to say that they were having bariatric surgery, you know. And I think until like stars and celebrities started coming out to actually say that, oh, yeah, I couldn't actually diet. Like there's no way, you know, I can keep this weight off naturally. (LaKeisha, 40, Female, Black)

I would probably talk to [friend's daughter who had bariatric surgery] about how it's going for her. But I don't want her to feel, because, see, that's the thing, the thing with the stigma. I don't want her to feel bad that I'm asking her about it. (Bettina, 52, Female, Black)

I guess people want to remain private, and just like the lady that I know that passed away, that's why she went to a second-rate hospital, because she didn't want anybody to know. Because she was a well-known figure in the city of [city], and she didn't want anybody to [know, and] it cost her life. (Sandra, 64, Female, African American) 
to be a person with obesity and suffering the social consequences of this stigma [23].

Society has stigmatized obese bodies, affecting individuals' perception of their bodies in the current state as well as how they would or would not like to change their bodies. Though these rules of stigma were created by society, stigmatized participants are burdened with responding. In line with Cahnman's "The Stigma of Obesity" in 1968 describing weight as a stigma, participants often placed blame of negative interactions upon themselves rather than others who imposed the stigma [28]. Since then, a large body of literature has documented how obesity stigma marginalizes individuals and impacts mental, physical, social, and economic health [29]. In line with obesity stigma, dieting and exercise were socially acceptable ways to lose weight which has also been found in a study by Lynch et al. examining perceptions of Black women [9]. In contrast, bariatric surgery was considered cheating and would bear social consequences of being looked down upon and talked about negatively. Additionally, similar to phenomenological studies by Moore et al. understanding perceptions of Black women and men, bariatric surgery in our study was seen as extreme and a last resort $[7,8]$. When participants perceive discipline of the body through self-work as the only legitimate way to maintain self-respect or authenticity, they lose an opportunity for better health.

Bariatric surgery, according to participants, also brought upon new social fears: being discovered. Having bariatric surgery would be a stigmatized action on top of the already stigmatized trait of obesity. Though undergoing bariatric surgery may not be apparent to others, it could devalue the person if discovered. This changed their main concern, according to Goffman, to "managing information about his failing" [23]. This was seen in participants' imagined fear of having their secret, that they had bariatric surgery, revealed to the world.

Thus, as healthcare providers who wish to reach more individuals and to encourage them to consider bariatric surgery, a life-saving and life-changing treatment, we need to understand better how to empathize with individuals whose health is threatened by obesity stigma. As providers caring for the whole person, we must address obesity stigma and engage individuals in a way that affirms their humanity [30-33]. This includes conscious and concerted efforts to use person-first language, "individuals with obesity" rather than "obese individuals," [34] and talking about bariatric surgery as "most effective" rather than a "last resort" [35]. Additionally, many individuals we spoke to had either been stigmatized personally or watched television shows related to bariatric surgery which enforced obesity stigma-related notions of bariatric surgery. As healthcare providers, we can further engage our patients in dialog directly about obesity stigma and how this manifests in our lived experiences from daily social interactions with others to the media to which we are exposed. Given the influential role of media, we may also find that one way to combat obesity stigma is to engage news outlets, give talks at churches or community centers, or appear on television shows to discuss bariatric surgery and its role in health.

With regard to health equity, we found in our study which centers Black voices that obesity stigma is the strongest reason for not considering bariatric surgery. Utilization of bariatric surgery among racial and ethnic minorities has been a long-standing issue. Wallace et al. demonstrated in 2010 using the Nationwide Inpatient Sample that one of the strongest predictors for not undergoing bariatric surgery was non-White race [36]. A decade later, as the data presented earlier regarding utilization of bariatric surgery by race and ethnicity in the Metabolic and Bariatric Surgery Accreditation and Quality Improvement Program (MBSAQIP) show, [6] we have not yet reached health equity in obesity treatment. Addressing stigma may be a way to effectively start to tackle health disparities in obesity.

We will also need to be careful about how we as providers shift the discourse of stigma. Previous research on bariatric surgery center websites showed removing moralizing tones rationalized failure of non-surgical solutions. However, when failures occurred after surgery, the healthcare system attributed those failures again to lack of individual willpower [37]. This focus solely on individual effort that comes from obesity stigma was also seen in bariatric surgery patients' own perceptions of their weight loss after surgery [38].

Our study has limitations. First, though our recruitment strategy included outreach to the community through postings in libraries and stores, most participants were recruited through our community partner. Thus, most participants were already connected to healthcare. There may be different beliefs held by individuals who do not engage healthcare at all. Despite this, our sample has diversity by age, race, and insurance status. Second, our study does not have adequate representation of Hispanic nor Asian American Pacific Islander individuals who may have different experiences than the majority of participants of this study. Finally, almost all participants had heard of bariatric surgery. It is possible individuals who have never heard about bariatric surgery may have beliefs different from what is presented in our conceptual framework. However, our recruitment materials do not use the words "bariatric surgery," so it is unlikely that these individuals participated because they had particularly strong opinions about bariatric surgery.

\section{Conclusion}

This qualitative study of community members who would qualify for bariatric surgery shows obesity stigma was the main reason individuals rejected bariatric surgery. This 
stigmatized belief was found across participants regardless of age or White or Black race. Society caused obesity to be a stigmatizing feature, but undergoing bariatric surgery would further stigmatize individuals. Thus, healthcare providers may be instrumental in increasing bariatric surgery uptake by shifting social discourse from stigmatized notions of obesity and weight loss towards one focusing on health and that addresses obesity stigma head on.

Supplementary Information The online version contains supplementary material available at https://doi.org/10.1007/s11695-022-05928-x.

Acknowledgements We would like to thank Western Wayne Family Health Centers-Inkster for partnering with us to amplify Black voices in research. WWFHC was vital in helping us to develop our interview instrument and recruitment materials and to reach out to the community.

\section{Declarations}

Ethics Approval All procedures performed in studies involving human participants were in accordance with the ethical standards of the institutional and/or national research committee and with the 1964 Helsinki Declaration and its later amendments or comparable ethical standards.

Consent to Participate Informed consent was obtained from all individual participants included in the study. Additional informed consent was obtained from all individual participants for whom identifying information is included in this article.

Conflict of Interest Dr. Chao receives funding from the Veterans Affairs Center for Clinical Management Research, VA Ann Arbor Healthcare System; this work does not represent the views of the United States government nor the Department of Veterans Affairs. Dr. Diaz receives funding from the Veterans Affairs Center for Clinical Management Research, VA Ann Arbor Healthcare System; this work does not represent the views of the United States government nor the Department of Veterans Affairs. Dr. Ghaferi is supported through grants from the Agency for Healthcare Research and Quality (Grant Nos.: 5K08HS02362 and P30HS024403) and a Patient Centered Outcomes Research Institute Award (CE-1304-6596). Dr. Ghaferi receives salary support from Blue Cross Blue Shield of Michigan as the Director of the Michigan Bariatric Surgery Collaborative. Dr. Dimick receives grant funding from the NIH, AHRQ, and BlueCross BlueShield of Michigan Foundation. Dr. Dimick is a cofounder of ArborMetrix, Inc., a company that makes software for profiling hospital quality and efficiency. Dr. Byrnes has no disclosures to report. The authors report no conflicts of interest relevant to this work.

\section{References}

1. Hales CM, Carroll MD, Fryar CD, et al. NCHS Data Brief, No 360: Prevalence of obesity and severe obesity among adults: United States, 2017-2018. National Center for Health Statistics. 2020.

2. Arterburn DE, Telem DA, Kushner RF, et al. Benefits and risks of bariatric surgery in adults: a review. JAMA. 2020;324(9):879-87.

3. Maciejewski ML, Arterburn DE, Van Scoyoc L, et al. Bariatric surgery and long-term durability of weight loss. JAMA Surg. 2016;151(11):1046-55.
4. Campos GM, Khoraki J, Browning MG, et al. Changes in utilization of bariatric surgery in the United States from 1993 to 2016. Ann Surg. 2020;271(2):201-9.

5. Race and Ethnicity in the United States: 2010 Census and 2020 Census. 2021. https://www.census.gov/library/visualizations/inter active/race-and-ethnicity-in-the-united-state-2010-and-2020-census.html. Accessed 1 March 2021.

6. The Metabolic and Bariatric Surgery Accreditation and Quality Improvement Program. https://www.facs.org/quality-programs/ mbsaqip. Published 2019. Accessed 13 Apr 2020.

7. Moore D, Cooper C, Davis-Smith YM. African American obese men's attitudes and perceptions of bariatric surgery: a phenomenological study. Spectrum: J Black Men. 2016;4(2):43-60.

8. Moore DD, Taylor C, Holland J, et al. African American obese women's perspectives regarding barriers to the utilization of bariatric surgery: a phenomenological study. J Black Stud. 2017;48(5):484-500.

9. Lynch CS, Chang JC, Ford AF, et al. Obese African-American women's perspectives on weight loss and bariatric surgery. J Gen Intern Med. 2007;22(7):908-14.

10. Imbus JR, Voils CI, Funk LM. Bariatric surgery barriers: a review using Andersen's Model of Health Services Use. Surg Obes Relat Dis. 2018;14(3):404-12.

11. Stanford FC, Jones DB, Schneider BE, et al. Patient race and the likelihood of undergoing bariatric surgery among patients seeking surgery. Surg Endosc. 2015;29(9):2794-9.

12. Funk LM, Jolles S, Fischer LE, et al. Patient and referring practitioner characteristics associated with the likelihood of undergoing bariatric surgery: a systematic review. JAMA Surg. 2015;150(10):999-1005.

13. Wee CC, Hamel MB, Apovian CM, et al. Expectations for weight loss and willingness to accept risk among patients seeking weight loss surgery. JAMA Surg. 2013;148(3):264-71.

14. Munoz DJ, Lal M, Chen EY, et al. Why patients seek bariatric surgery: a qualitative and quantitative analysis of patient motivation. Obes Surg. 2007;17(11):1487-91.

15. Wee CC, Huskey KW, Bolcic-Jankovic D, et al. Sex, race, and consideration of bariatric surgery among primary care patients with moderate to severe obesity. J Gen Intern Med. 2014;29(1):68-75.

16. Malterud K, Siersma VD, Guassora AD. Sample size in qualitative interview studies: guided by information power. Qual Health Res. 2016;26(13):1753-60.

17. [BLINDED]

18. Holstein JA, Gubrium JF. The active interview. Thousand Oaks: SAGE Publications; 1995.

19. Saldaña J. The coding manual for qualitative researchers. $3 \mathrm{E}$ [Third edition]. ed.

20. Miles MB, Huberman AM, Saldaña J. Qualitative data analysis: a methods sourcebook. Edition 3. ed.

21. Thorne SE. Interpretive Description : qualitative research for applied practice. Second edition. ed.

22. Wolcott HF, Sage Publications. Writing up qualitative research. In: 3rd ed. Los Angeles, [Calif.] ; London: SAGE; 2009: http:// methods.sagepub.com/book/writing-up-qualitative-research.

23. Goffman E. Stigma; notes on the management of spoiled identity. Englewood Cliffs: Prentice-Hall; 1963.

24. Link BG, Phelan JC. Stigma and its public health implications. Lancet. 2006;367(9509):528-9.

25. Wilson K, Luker KA. At home in hospital? Interaction and stigma in people affected by cancer. Soc Sci Med. 2006;62(7):1616-27.

26. Cruz ML, Bastos FI, Darmont M, et al. The, "moral career" of perinatally HIV-infected children: revisiting Goffman's concept. AIDS Care. 2015;27(1):6-9.

27. Pescosolido BA. Erving Goffman: the moral career of stigma and mental illness. Palgrave Handbook of Social Theory in Health, Illness and Medicine. 2015:273-286. 
28. Cahnman WJ. The stigma of obesity. Sociological Quarterly. 1968;9:293-9.

29. Pause C. Borderline: the ethics of fat stigma in public health. $\mathrm{J}$ Law Med Ethics. 2017;45(4):510-7.

30. Rubino F, Puhl RM, Cummings DE, et al. Joint international consensus statement for ending stigma of obesity. Nat Med. 2020;26(4):485-97.

31. Kuehn BM. Put an end to obesity stigma, International Panel Urges. JAMA. 2020;323(15):1435.

32. Berry EM. The obesity pandemic-whose responsibility? No blame, no shame, not more of the same. Front Nutr. 2020;7:2.

33. Rubin R. Addressing medicine's bias against patients who are overweight. JAMA. 2019;321(10):925-7.

34. Kyle TK, Puhl RM. Putting people first in obesity. Obesity (Silver Spring). 2014;22(5):1211.

35. Sogg S, Grupski A, Dixon JB. Bad words: why language counts in our work with bariatric patients. Surg Obes Relat Dis. 2018;14(5):682-92.
36. Wallace AE, Young-Xu Y, Hartley D, et al. Racial, socioeconomic, and rural-urban disparities in obesity-related bariatric surgery. Obes Surg. 2010;20(10):1354-60.

37. Salant T, Santry HP. Internet marketing of bariatric surgery: contemporary trends in the medicalization of obesity. Soc Sci Med. 2006;62(10):2445-57.

38. Meleo-Erwin ZC. 'No one is as invested in your continued good health as you should be': an exploration of the post-surgical relationships between weight-loss surgery patients and their home bariatric clinics. Sociol Health Illn. 2019;41(2):285-302.

Publisher's Note Springer Nature remains neutral with regard to jurisdictional claims in published maps and institutional affiliations. 